\title{
HUBUNGAN SIKAP IBU HAMIL TERHADAP HYPEREMESIS GRAVIDARUM TINGKAT SEDANG DI RUANG KASUARI RSU ANUTAPURA PALU
}

\author{
Wayan Wirawan ${ }^{1, *}$, Putu Suriyani ${ }^{2}$. \\ ${ }^{1}$ Akademi Farmasi Medika Nusantara Palu Sulawesi Tengah \\ ${ }^{2}$ Sekolah Tinggi Ilmu Kesehatan Widya Nusantara Palu.Palu Sulawesi Tengah. \\ *Corresponding author email : wirawanwayan9@gmail.com
}

\begin{abstract}
Pregnancy is a natural and physiological process. Any woman who has a healthy reproductive organs, Any woman who is pregnant will definitely experience Hyperemesis gravidarum mild, moderate or fallow. The purpose of this study is to determine the relationship Attitudes Against Hyperemesis gravidarum Pregnancy Rate Medium In Space cassowary RSU Anutapura Palu. The research in this study is a correlational study with descriptive analysis with cross sectional approach. The population in this study were all women with hyperemesis gravidarum in the room cassowary RSU Anutapura hammer, totaling 45 mothers with hyperemesis gravidarum. In this study using the analysis of univariate and bivariate significance invitation 0005 with 95\% confidence level continued to Chi Square test and simple regression which is used to examine the relationship maternal attitude towards Hyperemesis gravidarum moderate In Space cassowary RSU Anutapura Palu. And how much influence the attitude of Pregnant Women Against Hyperemesis Gravidarum Medium Level. Of the 31 respondents based test using bivariate analysis showed signivikansi value $0.000<0.05$ which means there signivikan correlation between the two variables and chi square test with 31 respondents diproleh signivikansinya value of $0.00<0.05$, which means that the statistics there is a relationship between attitudes towards pregnant women with hyperemesis gravidarum moderate level, followed by a simple regression obtained $F$ value hitung48,809 with a significance level of 0.000 $<0.05$, which means it has the effect of maternal attitudes towards hyperemesis grafidarum. In the results of the analysis show that there is a relationship attitude towards Hyperemesis gravidarum pregnant women being perceived level of pregnant mothers In Space cassowary RSU Anutapura Palu influence the level of $12.033 \%$
\end{abstract}

Keywords: Attitudes of pregnant women, Hyperemesis gravidarum

\begin{abstract}
ABSTRAK
Kehamilan merupakan suatu proses yang alamiah dan fisiologis. Setiap wanita yang memiliki organ reproduksi yang sehat, Setiap wanita yang hamil pasti akan mengalami Hiperemesis gravidarum tingkat ringan, sedang maupun berat. Tujuan penelitian ini yaitu untuk mengetahui Hubungan Sikap Ibu Hamil Terhadap Hyperemesis Gravidarum Tingkat Sedang Di Ruang Kasuari RSU Anutapura Palu. Jenis penelitian dalam penelitian ini merupakan penelitian dengan analisis deskriptif korelasional dengan pendekatan cross sectional. Cara pengambilan sampel secara aksidental sampling yaitu pengambilan sampel yang dilakukan dengan kebetulan bertemu dengan peneliti di ruang kasuari RSU Anutapura Palu, dengan jumlah sampel 31 responden. Dari 31 responden dengan menggunakan analisis bivariat menunjukan nilai signivikansi $0,000<$ 0,05 yang berarti terdapat korelasi yang signivikan antara dua variable dan uji Chi Square dengan 31 responden diproleh nilai signivikansinya $0,00<0,05$ yang berarti dilihat dari statistik ada hubungan antara sikap ibu hamil terhadap hiperemesis gravidarum tingkat sedang, dilanjutkan dengan regresi sederhana diperoleh nilai $\mathrm{F}$ hitung48,809 dengan tingkat signifikansi $0,000<0,05$ yang berarti mempunyai pengaruh sikap ibu hamil terhadap hiperemesis grafidarum. Kesimpulan dari penelitian ini ada hubungan sikap ibu hamil terhadap Hyperemesis Gravidarum tingkat sedang yang dirasakan ibu hamil Di Ruang Kasuari RSU Anutapura Palu dengan tingkat pengaruh sebesar 12,033\%
\end{abstract}

Kata Kunci : Sikap ibu hamil, Hiperemesis Gravidarum.

Submitted on: 8 November 2017 Accepted on: 1 December 2017

DOI: https://doi.org/10.25026/jsk.v1i8.83 
Hubungan sikap ibu hamil terhadap hyperemesis Gravidarum tingkat sedang di ruang Kasuari RSU anutapura Palu

\section{PENDAHULUAN}

Kehamilan merupakan suatu proses yang alamiah dan fisiologis. Setiap wanita yang memiliki organ reproduksi yang sehat, yang telah mengalami mensturasi dan melakukan hubungan seksual dengan seorang pria yang organ reproduksinya sehat sangat besar kemungkinan akan mengalami kehamilan. Apabila kehamilan direncanakan maka akan memberikan rasa kebahagiaan dan penuh harapan, dari hal tersebut perlunya asupan gizi kepada calon ibu untuk menjaga agar bayi tetap sehat.(Masroroh,2012).

Berdasarkan uraian di atas adapun Rumusan masalah dalam penelitian ini "apakah ada Hubungan Sikap Ibu Hamil Terhadap Hyperemesis Gravidarum Tingkat Sedang Di Ruang Kasuari RSU Anutapura Palu" Dengan tujuan untuk mengetahui Hubungan Sikap Ibu Hamil Terhadap Hyperemesis Gravidarum Tingkat Sedang Di Ruang Kasuari RSU Anutapura Palu.

\section{METODE PENELITIAN}

Jenis penelitian dalam penelitian ini merupakan penelitian dengan analisis deskriptif korelasional dengan pendekatan cross sectional. Cross sectional merupakan rancangan penelitian yang pengukuran atau pengamatannya dilakukan secara simultan pada satu saat (sekali waktu) (Alimul, 2012). Yang di ruangan kasuari RSU Anutapura palu. Yang mana Sampel dalam penelitian ini adalah semua ibu hiperemesis gravidarum yang kebetulan bertemu dengan penelitti di ruangan kasuari RSU anutapura palu berjumlah 31 responden

\section{HASIL DAN PEMBAHASAN}

Berdasarkan tabel 1 menunjukkan bahwa, dari 31 responden sebagian besar responden dewasa awal (26-35 thn) yaitu sebanyak 15 responden dengan presentase 48,39\%, Dewasa Akhir (36-45 thn) sebanyak 10 responden dengan presentase $32,26 \%$ dan Remaja Akhir (17-25 thn) sebanyak 6 responden dengan presentase $19,35 \%$.

Berdasarkan table 2 menunjukkan bahwa, dari 31 responden, sebagian besar responden dengan Pendidikan dasar ( SD,SMP) yaitu sebanyak 16 responden dengan presentase $51,61 \%$, Pendidikan tinggi (D1,S2) sebanyak 8 responden dengan presentase $25,80 \%$ dan Pendidikan menengah (SMA) sebanyak 7 responden dengan presentase $22,58 \%$.

Tabel 1 Distribusi frekuensi karakteristik responden menurut umur di ruang kasuari Rumah Sakit Daerah Anutapura Palu

\begin{tabular}{lcc}
\hline Umur & Frekuensi (f) & Persentase $(\%)$ \\
\hline Remaja Akhir (17-25 thn) & 6 & 19,35 \\
Dewasa Awal (26-35 thn) & 15 & 48,39 \\
Dewasa Akhir (36-45 thn) & 10 & 32,26 \\
\hline Jumlah & 31 & 100
\end{tabular}

Tabel 2 Distribusi frekuensi karakteristik responden berdasarkan pendidikan di ruang kasuari Rumah Sakit Daerah Anutapura Palu

\begin{tabular}{ccc}
\multicolumn{1}{c}{ Pendidikan } & Frekuensi (f) & Persentase (\%) \\
\hline Pendidikan dasar ( SD,SMP) & 16 & 51,61 \\
Pendidikan menengah (SMA) & 7 & 22,58 \\
Pendidikan tinggi (D1,S2) & 8 & 25,80 \\
\hline Jumlah & 31 & 100 \\
\hline
\end{tabular}

Sumber : data primer, 2015 
Hubungan sikap ibu hamil terhadap hyperemesis Gravidarum tingkat sedang di ruang Kasuari RSU anutapura Palu

Tabel 3. Distribusi frekuensi karakteristik responden berdasarkan pekerjaan di ruang kasuari Rumah Sakit Daerah Anutapura Palu

\begin{tabular}{ccc}
\hline Pekerjaan & Frekuensi (f) & Persentase (\%) \\
\hline Ibu rumah tangga & 13 & 41,93 \\
Pegawai & 14 & 45,16 \\
Mahasiswa & 4 & 12,90 \\
\hline Jumlah & 31 & 100
\end{tabular}

Sumber : data primer, 2015

Tabel.4. Distribusi Sikap ibu hamil terhadap hiperemesis gravidarum tingkat sedang di ruangan kasuari Rumah Sakit Daerah Anutapura Palu

\begin{tabular}{lcc}
\hline \multicolumn{1}{c}{ Sikap ibu hamil } & Frekuensi (f) & Presentase $(\%)$ \\
\hline Sangat Setuju & 47 & 15,16 \\
Setuju & 210 & 67,74 \\
Tidak Setuju & 47 & 15,16 \\
Sangat Tidak Setuju & 6 & 1,93 \\
\hline \multicolumn{1}{c}{ Total } & 310 & $100 \%$
\end{tabular}

Sumber : data primer 2015

Tabel 5. Distribusi cara mengatasi hiperemesis gravidarum tingkat sedang di ruangan kasuari Rumah Sakit Daerah Anutapura Palu

\begin{tabular}{lcc}
\hline Hiperemesis gravidarum & Frekuensi (f) & Presentase $(\%)$ \\
\hline Sangat Setuju & 48 & 15,48 \\
Setuju & 194 & 62,58 \\
Tidak Setuju & 62 & 20 \\
Sangat Tidak Setuju & 6 & 1,93 \\
\hline \multicolumn{1}{c}{ Total } & 310 & $100 \%$ \\
\hline
\end{tabular}

Sumber : data primer 2015

\section{ANALISIS UNIVARIAT}

Berdasarkan table 3 menunjukkan bahwa, dari 31 responden, sebagian besar responden dengan pegawai yaitu sebanyak 14 responden dengan presentase $45,16 \%$, Ibu rumah tangga sebanyak 13 responden dengan presentase $41,93 \%$ dan pekerjaan sebagai Mahasiswa sebanyak 4 responden dengan presentase $12,90 \%$. Pernyataan setuju sebesar 210 dengan presentase $67,7 \%$, untuk pernyataan sangat setuju dan tidak setuju sama dengan perolehan nilai sebesar 47 dengan presentase $15,16 \%$ dan untuk pernyataan sangat tidak setuju dengan nilai 6 dengan presentase 1,93\%.

Berdasarkan table 5 menunjukkan bahwa, dari 31 responden, sebagian besar pernyataan tentang hiperemesis gravidarum tingkat sedang pernyataan setuju sebesar 194 dengan presentase $62,58 \%$, untuk pernyataan tidak setuju sebesar 62 dengan presentase $20 \%$ dan untuk pernyataan sangat setuju sebesar 48 dengan presentase $15,48 \%$ dan untuk pernyataan yang merespon paling sedikit adalah sangat tidak setuju dengan nilai 6 dengan presentase $1,93 \%$. 
Hubungan sikap ibu hamil terhadap hyperemesis Gravidarum tingkat sedang di ruang Kasuari RSU anutapura Palu

\section{ANALISIS BIVARIAT}

Tabel 6. Hubungan sikap ibu hamil terhadap hiperemesis gravidarum tingkat sedang di ruangan kasuari Rumah Sakit Daerah Anutapura Palu

Correlations

\begin{tabular}{llcc}
\hline & & Sikap ibu & Hiperemesis gravidarum \\
\hline Sikap ibu & Pearson Correlation & 1 & $.792^{* *}$ \\
& Sig. (2-tailed) & & .000 \\
& $\mathrm{~N}$ & 31 & 31 \\
\hline Hiperemesis & Pearson Correlation & $.792^{* *}$ & 1 \\
gravidarum & Sig. (2-tailed) & .000 & 31 \\
& $\mathrm{~N}$ & 31 & \\
\hline
\end{tabular}

**. Correlation is significant at the 0.01 level (2-tailed).

Sumber : data primer 2014

Tabel 7. Uji Chi square

Chi-Square Tests

\begin{tabular}{llll}
\hline & Value & Df & Asymp. Sig. (2-sided) \\
\hline Pearson Chi-Square & $57.488^{\mathrm{a}}$ & 48 & .000 \\
Likelihood Ratio & 53.241 & 48 & .000 \\
Linear-by-Linear Association & 18.819 & 1 & .000 \\
N of Valid Cases & 31 & & \\
\hline
\end{tabular}

a. 63 cells $(100.0 \%)$ have expected count less than 5 . The minimum expected count is .06 .

Symmetric Measures

\begin{tabular}{llcccc}
\hline & Value & Asymp. Std. Error & Approx. T & Approx. Sig. \\
\hline Interval by Interval & Pearson's R & .792 & .060 & 6.986 & $.000^{\mathrm{c}}$ \\
Ordinal by Ordinal & Spearman Correlation & .827 & .046 & 7.921 & $.000^{\mathrm{c}}$ \\
N of Valid Cases & & 31 & & & \\
\hline
\end{tabular}

a. Not assuming the null hypothesis.

b. Using the asymptotic standard error assuming the null hypothesis.

c. Based on normal approximation. 
Hubungan sikap ibu hamil terhadap hyperemesis Gravidarum tingkat sedang di ruang Kasuari RSU anutapura Palu

Tabel 8. Analisis regresi sederhana

\begin{tabular}{|c|c|c|c|c|c|c|}
\hline \multicolumn{7}{|c|}{ ANOVA $^{\mathrm{b}}$} \\
\hline & Model & Sum of Squares & Df & Mean Square & $\mathrm{F}$ & Sig. \\
\hline \multirow[t]{3}{*}{1} & Regression & 73.616 & 1 & 73.616 & 48.809 & $.000^{\mathrm{a}}$ \\
\hline & Residual & 43.739 & 29 & 1.508 & & \\
\hline & Total & 117.355 & 30 & & & \\
\hline $\begin{array}{l}\text { a. } \\
\text { GRA }\end{array}$ & $\begin{array}{l}\text { Predictors: } \\
\text { DARUM }\end{array}$ & (Constant), & VI & & & \\
\hline
\end{tabular}

b. Dependent Variable: SIKAP IBU

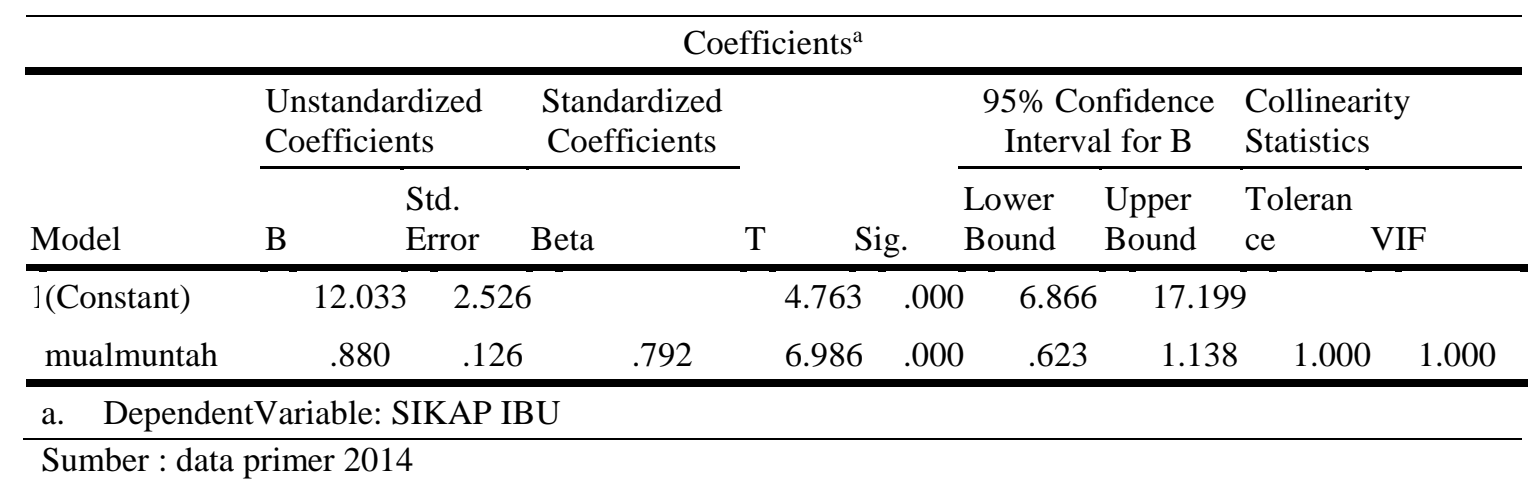

Berdasarkan tabel 6 untuk melihat Hubungan sikap ibu hamil terhadap hiperemesis gravidarum tingkat sedang di ruangan kasuari Rumah Sakit Daerah Anutapura Palu diketahui antara sikap ibu hamil (X1) terhadap hiperemesis gravidarum (X2) dengan perolehan nilai signivikansi $0,000<0,05$ yang berarti terdapat korelasi yang signifikan.

\section{Analisis cis-square.}

Berdasarkan hasil uji Chi-Square pada tabel 7 dengan 31 responden diperoleh nilai signifikansinya $0,00<$ 0,05 brarti dilihat secara statistic ada hubungan antara sikap ibu hamil terhadap hiperemesis gravidarum yang di alami oleh pasien di ruang kasuari Rumah Sakit Umum Daerah Anutapura Palu.

Berdasarkan hasil uji regresi sederhana pada tabel 8 dimana diperoleh nilai $\mathrm{F}$ hitung 48.809 dengan tingkat signifikansi $0,000<0,05$ maka sikap ibu hamil mempunyai pengaruh terhadap hipepemesis grafidarum, dengan nila pengaruh sebesar 12,033.

\section{PEMBAHASAN}

1. Sikap ibu hamil terhadap hiperemesis gravidarum tingkat sedang

Berdasarkan hasil penelitian hubungan sikap ibu hamil terhadap hiperemesis grevidarum tingkat sedang dengan menggunakan analisis univariat menunjukan 310 pernyataan dari 31 responden dimana diperoleh 210 $(67,74 \%)$ menyatakan setuju, 47 $(15,16 \%)$ menyatakan sangat setuju, 6 $(1,93 \%)$ menyatakan sangat tidak setuju, dan $47(15,16 \%)$ menyatakan tidak setuju.

Menurut asumsi peneliti, dari hasil penelitian ini, sikap ibu terhadap hiperemesis gravidarum tingkat sedang di ruangan kasuari Rumah Sakit Daerah 
Anutapura Palu sebagian besar sudah menunjukan perubahan sikap terhadap kehamilan sehingga hiperemesis gravidarum dapat ditangani secara perlahan. Hal ini disebabkan pada saat ini masyarakat khususnya ibu hamil mendapatkan penyuluhan- penyuluhan yang dilakukan oleh petugas kesehatan. Oleh sebab itu untuk lebih mengoptimalkan sikap ibu hamil terhadap hiperemesis gravidarum perlu adanya pengarahan-pengarahan yang lebih mendalam.

Penelitian ini sejalan dengan azwar (2010), sikap dapat berubah melalui tiga proses yaitu kesediaan, identifikasi, dan internalisasi. Kesediaan terjadi ketika individu bersedia menerima pengaruh dari orang lain. Dikarenakan individu berhak memperoleh reaksi atau tanggapan positif. Indentifikasi terjadi saat individu meniru prilaku atau sikap seseorang yang dikarenakan sikap tersebut sesuai dengan apa yang dianggap individu sebagai bentuk hubungan yang meyenangkan antara individu dengan pihak lain. Internalisasi terjadi saat individu menerima pengaruh dan bersediaan bersikap menuruti pengaruh itu dikarenakan sikap tersebut sesusuai dengan apa yang dipercayai individu.

Menurut surwono (2007)

menyatakan perubahan sikap dan perilaku individu dimulai dengan tahap indentifikasi, kemudian baru menjadi internalisasi. Motivasi merupakan manifestasi dari sikap yang mana merupakan perilaku yang berkaitan erat dengan sikap individu itu sendiri. Motivasi merupak daya yang menggerakan manusia untuk berperilaku. Motivasi dimulai mula-mula individu mematuhi anjuran atau intruksi yang dikarenakan ingin menghindari kekambuhan penyakit.
2. Cara mengatasi hiperemesis gravidarum tingkat sedang

Berdasarkan hasil analisis univariat yang dilakukan untuk mengetahui cara mengatasi hiperemesis gravidarum tingkat sedang dari 31 responden dalam 310 pernyataan, dimana diperoleh $48(15,48 \%)$ sangat setuju, 194 $(62,58 \%)$ setuju, $62(20 \%)$ tidak setuju, dan $6(1,93 \%)$ sangat tidak setuju.

Menurut asumsi peneliti, dilihat dari data yang diperoleh sebagian besar masyarakat sudah mampu mengambil keputusan yang dilakukan dalam mengatasi hiperemesis gravidarum tingkat sedang yang dialami sang calon ibu, oleh sebab itu faktor kedewasaan seseorang berhubungan dengan kemampuannya dalam mengatasi kondisi yang dialami. Hal ini dapat dibuktikan pada responden ibu hamil di ruangan kasuari Rumah Sakit Daerah Anutapura Palu, dimana sebagian besar responden telah melakukan upaya dalam mengatasi hiperemesis gravidarum tingkat sedang.

Penelitian ini sejalan dengan, Srianingsih, Mellita S.A (2013) yang menyatakan kematangan yang dimiliki seorang berhubungan erat dengan kemampuannya, salah satunya keadaan kesehatan yang terkait hiperemesis gravidarum sehinggga memerlukan beberapa Cara mengatasi hiperemesis gravidarum antaralain. Makan dalam jumlah sedikit tapi sering sehingga tidak bertambah mual, makan-makanan yang tinggi karbohidrat dan protein yang dapat membantu dalam mengatasi mual muntah. Hindari makanan yang berlemak yang dapat menambah rasa mual, serta minum yang cukup untuk menghindari dehidrasi pada saat mual muntah. 
Hubungan sikap ibu hamil terhadap hyperemesis Gravidarum tingkat sedang di ruang Kasuari RSU anutapura Palu

1. Hubungan sikap ibu hamil terhadap hiperemesis gravidarum tingkat sedang

Berdasarkan hasil penelitian hubungan sikap ibu hamil terhadap hiperemesis grevidarum tingkat sedang dengan menggunakan analisis bivariat diperoleh nilai signivikansi $0,000<0,05$ yang berarti terdapat korelasi yang signifikan. Serta di lihat dari nilai pearson correlation yang dihubungkan antara masing-masing variable mempunyai tanda bintang, berarti terdapat korelasi yang signifikan antara variable yang dihubungkan. Yang mana diperjelas dengan hasil uji analisis chi-square dengan 31 responden diperoleh nilai signifikansi $=0,00$ atau probabilitas dibawah $0,05(0,00<0,05)$ maka $\mathrm{H}_{0}$ ditolak, sehingga dengan demikian adanya hubungan antara sikap ibu hamil dengan hiperemesis gravidarum tingkat sedang yang dirasakan ibu hamil di ruang kasuari Rumah Sakit Umum Daerah Anutapura Palu. Dengan pengaruh sebesar 12,033 dengan nilai $F$ hitung 48.809 yang mempunyai tingkat signifikansi $0,000<0,05$ hal ini menunjukkan pengaruh secara bersamasama antar variabel. Maka berdasarkan hasil yang diperoleh dalam penelitian ini, hipotesis yang menyatakan pengaruh/hubungan dari masing-masing variabel dengan standar kesalahan yang dapat diperkirakan sebesar 2,256.

Menurut asumsi peneliti, dari hasil penelitian ini, menunjukan hasil analisis yang dilakukan, pendidikan dalam bidang kesehatan yang diperoleh pada masyarakat khususnya ibu hamil yang dierikan tenaga kesehatan sehingga mampu melakukan upaya-upaya dalam mengatasi hiperemesis gravidarum. Dimana semakin sering pemahaman/pendidikan yang diberikan maka semakin tinggi pula pemahaman ibu hamil dalam mengatasi hiperemesis gravidarum.

Hasil penelitian ini sejalan dengan notoadmojo,(2012) sikap merupakan reaksi/respon yang masi tertutup dari seseorang terhadap suatu stimulus atau reaksi yang berdasarkan pengalaman, kebudayaan, pengaruh orang lain serta pengaruh faktor emosional yang nantinya dapat mempengaruhi keputusan seseorang terhadap suatu tindakan yang nantinya dilakukan.

\section{KESIMPULAN}

Berdasarkan hasil penelitian dan pembahasan pada bab sebelumnya, dapat ditarik kesimpulan sebagai berikut:

1. Distribusi sikap ibu hamil terhadap hiperemesis gravidarum tingkat sedang di ruang Kasuari RSU anutapura palu.

2. Distribusi cara mengatasi hiperemesis gravidarum tingkat sedang di ruang Kasuari RSU anutapura palu.

3. Ada hubungan yang signifikan antara hubungan sikap ibu hamil dengan hiperemesis gravidarum tingkat sedang di ruang Kasuari RSU anutapura palu.

\section{DAFTAR PUSTAKA}

[1]. Masroroh.,2012"Hubungan Pengetahuan Ibu Hamil Tentang Ketidak Nyamanan Kehamilan Dengan Sikam Dalam Mengatasi Ketidak nyamanan Kehamilan" .Ed 1. Uniska Kendal Hal 2.

[2]. Waryono, 2010. "Keperawatan Keluarga". Ed 5, Bandung Hal 6.

[3]. Asmawahyunita.2012." Hubungan Sikap Ibu Tentang alat kontrasepsi dalam rahim dengan pemilihan alat kontrasepsi dalam rahim”. Ed 2. Jepara Hal. 1

[4]. Rahmaniar MB, Baharudin Bahar. 2013." Faktor-faktoryang berhubungan dengan kekurangan e nergi kronis pada ibu hamil". Ed 4. Hasanudin Makasar. Hal 99. 
Hubungan sikap ibu hamil terhadap hyperemesis Gravidarum tingkat sedang di ruang Kasuari RSU anutapura Palu

[5]. DwijayantiR.M.,Oyoh.2013."Hubungan pengetahuan suami dengan partisipasi suamiterhadap kehamilan dibalai pengobatan sumber sehat marga asih kabupate bandung" Ed 2. Cimahi Hal 2.

[6]. Hani.U,Kusbandiah.J.DKK.2010.”Asuhan kebidanan pada kehamilan fisiologis". Malang. Hal 5.

[7]. Asmawahyunita.2012." Hubungan sikap ibu tentang alat kontrasepsi dalam rahim dengan pemilihan alat kontrasepsi dalam rahim". Ed 2. Jepara Hal 2.
[8]. Asmawahyunita.2012." Hubungan sikap ibu tentang alat kontrasepsi dalam rahim dengan pemilihan alat kontrasepsi dalam rahim". Ed 2. Jepara Hal 2.

[9]. Astuti Maya.2011."Buku pintar kehamilan" Bandung.,Hal 25.

[10]. Notoatmodjo,2010..Pendidikan dan perilaku kesehatan. Jakarta : Rineka Cipta;. Hal 124125. 